\title{
ХАРАКТЕРИСТИКА РАСПРЕДЕЛЕНИЯ ПРОРЫВОВ ГЛИНИСТЫХ ОТЛОЖЕНИЙ В ГОРНЫЕ ВЫРАБОТКИ ИЗ ВЫШЕЛЕЖАЩИХ ОСАДОЧНЫХ ПОРОД
}

\author{
Ефремов Евгений Юрьевич, \\ Efremov-eu@mail.ru \\ Институт горного дела УрО РАН, \\ Россия, 620219, г. Екатеринбург, ул. Мамина-Сибиряка, 58
}

\begin{abstract}
Актуальность. Прорывы воды и обводненных осадочных масс в горные выработки представляют серьезную угрозу для добычи полезных ископаемых подземным способом. За последние два десятка лет на шх. «Соколовская» произошел ряд аварий, связанных с прорывами глинистых масс в выработанное пространство. Самая масштабная из них привела к гибели двух человек, на восстановление рудника ушло несколько месяцев.

Цель: определение источников повышенного водного питания зоны обрушения для снижения риска прорывов обводненных глинистых масс на горизонты выпуска в условиях производства работ под водоносными горизонтами осадочного чехла.

Методы: анализ прорывов отложений, произошедших за период с 2003 по 2017 гг. В качестве критерия классификации используется объём глинистых пород, проникающих в горные выработки во время отдельного зарегистрированного прорыва. Выявление особенностей пространственного и временного распределения классифицированных аварий. Геостатистический анализ параметров водоносных горизонтов. Сопоставление параметров водоносных горизонтов и распределения аварий.

Результаты. Основная часть крупных прорывов приурочена к очистным работам на нижних рабочих горизонтах, в области обрушения северной и центральной групп воронок. Прорывы происходят, как правило, во время начальной стадии отработки рудного тела на нижнем горизонте, в дальнейшем их частота и объем снижаются. Необходимым условием формирования масштабных прорывов является повышенная обводненность области обрушения. Источниками повышенного питания групп воронок центральной и северной являются области высоких остаточных водяных столбов Мелового водоносного горизонта на севере и западе. Основным путем снижения прорывов является рациональная организация осушения массива пород вмещающего месторождения, направленная на целевое осушение обводненных участков Мелового горизонта.
\end{abstract}

Ключевые слова:

Воронка обрушения, область обрушения, водопритоки, прорыв, глинистые отложения, затопление.

\section{Введение}

Прорывы воды и обводненных масс в горные выработки являются источником серьезных аварийно-опасных и катастрофических явлений на подземных рудниках. В мировой практике одна из самых масштабных катастроф произошла в 1970 г. на руднике "Mufulira», Замбия. Хвосты обогащения проникли в горные выработки сквозь обрушенные породы на глубину более километра, во время аварии погибло 89 человек, значительная часть рудника выведена из строя на несколько лет $[1,2]$.

В последние годы, по сравнению с другими странами, остро стоит проблема в КНР. С 2000 по 2013 гг. произошел 1131 инцидент, где погибло 4533 человека. Около трети человек погибло в авариях с массовой гибелью людей (более 10 человек - 94 случая, более 30 человек - 9 случаев) [3].

Причинами большинства крупнейших аварий, связанных с затоплением подземных рудников, являются неправильное размещение хвостов производства или прорывы воды из старых затопленных горных выработок [4-6].

На территории РФ в последние годы крупнейшими авариями являются затопление в 2003 г. шх. «Западная-Капитальная» в Ростовской области [7] и затопление рудника Мирный в Якутии. Обе аварии сопровождались человеческими жертвами, первая послужила причиной ликвидации шахты, вторая - консервацией рудника, как ми- нимум до 2020 г. [8]. Источником опасности в первом случае являлись заполненные водой горные выработки ликвидированной шахты, во втором вода в карьере, расположенном над шахтой

Наряду с упомянутыми источниками аварий, серьезную угрозу подземным горным работам представляют прорывы воды и глинистых масс из вышележащих осадочных отложений. Эта проблема может сопутствовать-разработке угольных [9-11] и рудных месторождений. Примерами последних являются аварии на рудниках Темир-Тау, Шерегешское, Таштагольское, Гороблагодатское и др. [12].

Одним из ярких примеров среди этого ряда является шх. «Соколовская», РК. Прорывы песчаноглинистых масс в горные выработки явились причиной неоднократных аварий. Самая масштабная из них привела к гибели двух человек, в горные выработки попало свыше 37 тыс. м $^{3}$ отложений [13].

Изучение геологических и геотехнических особенностей, сбор информации и ее интерпретация являются ключом к учету опасностей при подземных горных работах [14]. При разработке месторождения системой с обрушением кровли в условиях вышележащего осадочного чехла в деятельности, направленной на снижение опасности прорывов в горные выработки, требуется учитывать особенности формирования и накопления обводненных отложений в зоне обрушения и их переноса на горизонты выпуска. 


\section{Условия разработки месторождения}

Шахта «Соколовская» расположена на северном фланге Соколовского месторождения, добыча руды ведется подземным способом системой с обрушением кровли. Отметка земной поверхности составляет около $185 \mathrm{m.}$

Месторождение перекрыто осадочным чехлом, мощность которого составляет около 110 м. В Осадочных породах прослеживается два основных водоносных горизонта.

Олигоценовый водоносный горизонт. Абсолютная отметка уровня подземных вод 176 м, мощность 5 м. Водовмещающими породами являются олигоценовые пески с коэффициентом фильтрации до $5 \mathrm{~m} /$ сутки, мощность песков достигает 8-9 м. Подошва горизонта сложена чеганскими глинами, мощностью 20-30 м.

Верхнемеловой меловый водоносный горизонт. Водовмещающими породами являются меловые пески, мощность песков около 36 м, коэффициент фильтрации до 10 м/сутки. На данный момент абсолютная отметка уровня воды составляет около 94 м. Основание водоносного горизонта сложено глинами коры выветривания, местами пески залегают на палеозойском фундаменте.

На поверхности шахтного поля сформировалась зона обрушения, обладающая сложным строением. Размер области обрушения составляет 1,6 км по простиранию и 0,6 км вкрест. Многочисленные первичные и повторные выходы объединены в четыре группы, в общих чертах соответствуя геометрии отработанных рудных тел.

В институте ВИОГЕМ под руководством Д.М. Казикаева был проведен ряд исследований на стендах из эквивалентных материалов, в ходе которых были выявлены закономерности проникновения глинистых осадочных пород на горизонты выпуска на Соколовском месторождении [15]. При обрушении кровли, после посадки междукамерных целиков, быстро формируется трубообразная воронка обрушения, достигающая земной поверхности практически с любой глубины (исследования проводились до глубины 400 м, на данный момент глубина очистных работ превышает $500 \mathrm{M}$, характер обрушения не поменялся). Высокоподвижные обводненные песчано-глинистые массы при этом легко проникают на горизонт выпуска двумя вариантами:

1) непосредственно через воронку обрушения и оперяющие зияющие трещины, благодаря постоянному относительному перемещению кусков обрушенных скальных пород;

2) через образующиеся пустоты, заполненные глинистым материалом. Пустоты сохраняются какое-то время в нетронутом состоянии, опускаются вслед за извлечением руды. Пустоты разрушаются при приближении к почве очистной единицы, выпуская отложения в пространство горизонта выпуска.

Основными факторами, влияющими на процесс проникновения глинистых отложений, явля- ются: наличие обширных каналов перепуска в пространстве нарушенного массива, образующегося вследствие обрушения кровли, и обводненность массива.

Как показали последние исследования, проникновению отложений через толщу нижерасположенных скальных пород способствуют тиксотропные свойства чеганских глин [16] в условиях естественной и техногенной сейсмичности [17] и геодинамической активности $[18,19]$.

Задачей исследований является анализ наблюдаемых случаев прорывов глинистых отложений на горизонты выпуска с целью выявления закономерностей и особенностей, позволяющих снизить ущерб, причиняемый производству.

\section{Анализ выходов песчано-глинистых отложений}

Исходными данными для анализа служили результаты мониторинга прорывов песчано-глинистых отложений (ПГО), фиксирующие дату и локализацию выходов отложений, их вещественный состав и комментарии.

Для анализа все выходы ПГО классифицированы на три категории в соответствии с масштабом проявления. $\mathrm{K}$ первой категории относятся масштабные выходы ПГО, вызывающие закрытие скреперных выработок и/или проникающие в зону откаточных выработок. Как правило, такой выход вызывает закрытие откаточных выработок на несколько дней или недель. Ориентировочные объемы ПГО превышают сотню и могут достигать нескольких тысяч кубических метров. Вторая категория включает выходы ПГО, влияющие на работу одной скреперной выработки, в т. ч. вызывающие перекрытие одной или нескольких выпускных воронок. Максимальный объем вышедших ПГО, попавших во вторую категорию, составляет первые десятки кубических метров. Третья категория включает появление элементов ПГО в составе пород, добываемых из очистной единицы, практически не влияющих на очистные работы. Максимальный объем отложений, попадающий в третью категорию, не превышает нескольких кубических метров (таблица).

В связи с тем, что объём выходов ПГО в журнале не фиксировался, ориентировочный средний объём определен по экспертным оценкам, на основе габаритов выработок, и может отличаться от реального.

Дальнейший анализ заключался в сопоставлении пространственного и временного распределения выходов отложений с геологическим строением месторождения, строением области обрушения, периодичностью и положением очистных работ, геотехнической, гидрогеологической информацией.

На рис. 1 приведен график ориентировочного объема поступлений отложений на горизонты выпуска по времени. Следует отметить, что общий объем вышедших отложений во время аварии 2005 г. составляет около 38 тыс. $\mathrm{M}^{3}$, примерно в 55 раз превышает средний объем выходов I катего- 
рии, и не может быть адекватно отражен в масштабе графика. Из рис. 1 видно, что объемы поступления глинистых отложений за разные периоды крайне неравномерны.

При привлечении данных по времени и срокам отработки очистных единиц прослеживается, что выходы отложений приурочены к циклу отработки рудного тела и сосредоточены на начальной стадии отработки рудного тела.

Для рассмотрения пространственного распределения выходов осадочных отложений на основе планов горных работ была создана упрощенная цифровая модель предприятия, включающая положение очистных единиц на горизонтах выпуска и положение воронок на земной поверхности.

Основное упрощение касается формы очистных единиц, их горизонтальное сечение предполагается неизмененным, а за высоту очистной единицы принята разница отметок между горизонтами выпуска. На данную модель нанесены положения зафиксированных выходов ПГО в соответствии с разработанной классификацией.

В связи с тем, что земная поверхность многократно подрабатывалась очистными работами на разных горизонтах, зона обрушения содержит большое количество повторных воронок, которые выходят на поверхность ликвидированных (засыпанных скальной массой) воронок. В результате этого зона обрушения представляет собой четыре относительно независимые группы воронок. Проведенные исследования объемов воронок показали, коэффициент разрыхления обрушенного массива изменяется с глубиной очистных работ, в за- висимости от соотношения осадочных и скальных пород в массиве над очистными единицами [20].

таблица. Классификация зарегистрированных выходов глинистых отложений

Table. Classification of registered mud inrushes

\begin{tabular}{|c|c|c|c|c|}
\hline 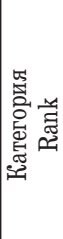 & 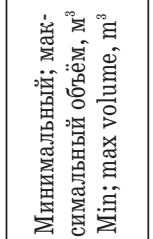 & 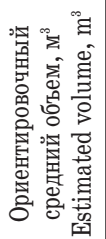 & $\begin{array}{c}\text { Характеристика } \\
\text { Characteristic }\end{array}$ & 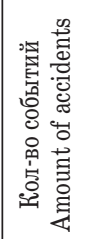 \\
\hline I & $(100 ; 40000)$ & 520 & \begin{tabular}{|l|} 
Приводит к закрытию скре- \\
перных выработок или ча- \\
стичному подтоплению отка- \\
точных выработок \\
Mud causes slusher drift clo- \\
sing or mud partially floods the \\
haulage drift
\end{tabular} & 21 \\
\hline II & $(8 ; 100)$ & 60 & $\begin{array}{l}\text { Влияние на работу скреперной } \\
\text { выработки } \\
\text { Mud affects the mode of opera- } \\
\text { tion in the slusher drift }\end{array}$ & 18 \\
\hline III & $(0 ; 8)$ & 4 & $\begin{array}{l}\text { Появление в составе скальных } \\
\text { пород } \\
\text { Mud appears among ore in the } \\
\text { finger raise }\end{array}$ & $19(58) *$ \\
\hline
\end{tabular}

* Без скобок - количество независимых событий, зарегистрированных в различных очистных единицах, в скобках - количество связанных событий, включающих повторные выходы отложений в одной очистной единице.

* Amount of isolated accident in isolated finger raises is without pa renthesis; amount in parenthesis includes series of accidents in same finger raises.

\section{Объем выходов ПГО на горизонты выпуска}

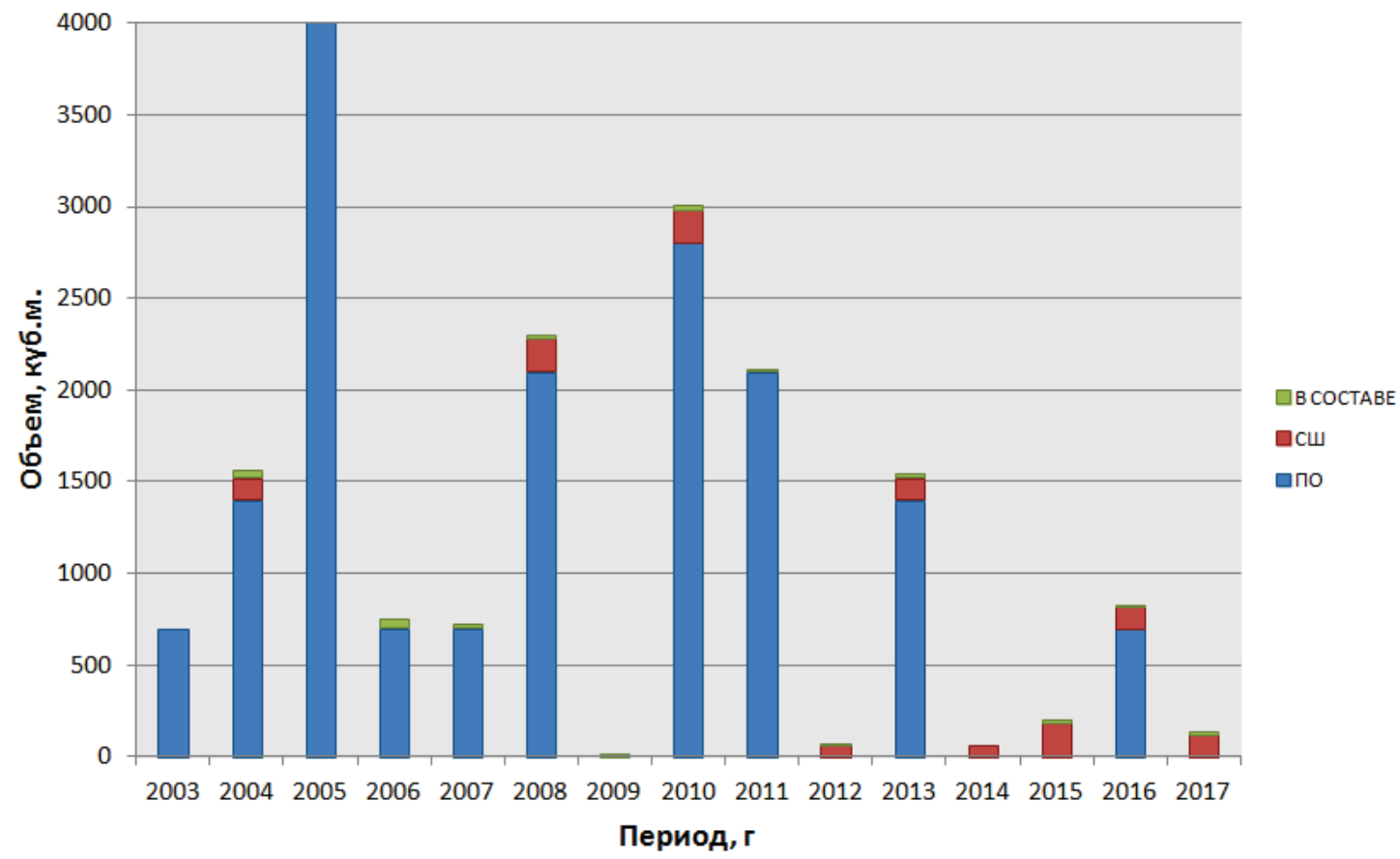

Рис. 1. График объемов поступлений ПГО в выработанное пространство

Fig. 1. Diagram of mud volume in flooded underground working 


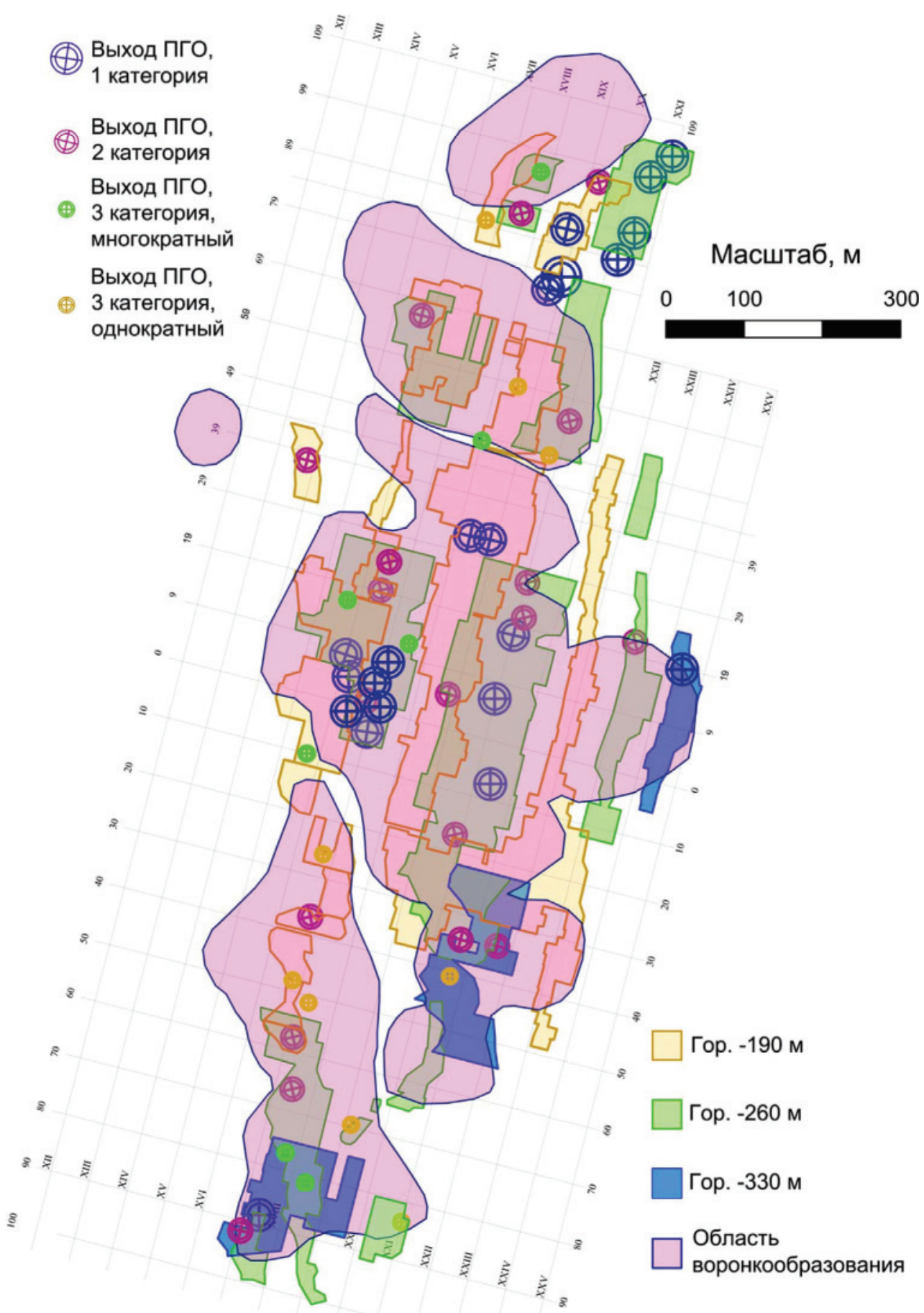

Рис. 2. Положение выходов ПГО из зоны обрушения

Fig. 2. Spatial distribution of mud inrushes from the caved zone

На рис. 2 изображены горизонты выпуска, на которых фиксировались положения выходов отложений, их категории и положение групп воронок на земной поверхности.

Из рис. 2 видно, что более 70 \% выходов ПГО первой категории локализуются в нескольких очистных единицах горизонтов -190 и -260 м, расположенных на двух участках месторождения. Первый из участков включает очистные единицы, расположенные в центральном рудном теле, в гра- ницах линий 9-10 координатной системы предприятия. Второй расположен на северном фланге месторождения, в границах линий 79-105. Этим участкам соответствуют две объединенные группы воронок. Выходы воронок на поверхность отклоняются на запад, в сторону лежачего бока, вследствие наклонного строения рудного тела.

Всего на поверхности месторождения присутствуют четыре группы объединенных воронок, однако большинство выходов ПГО связаны лишь с 


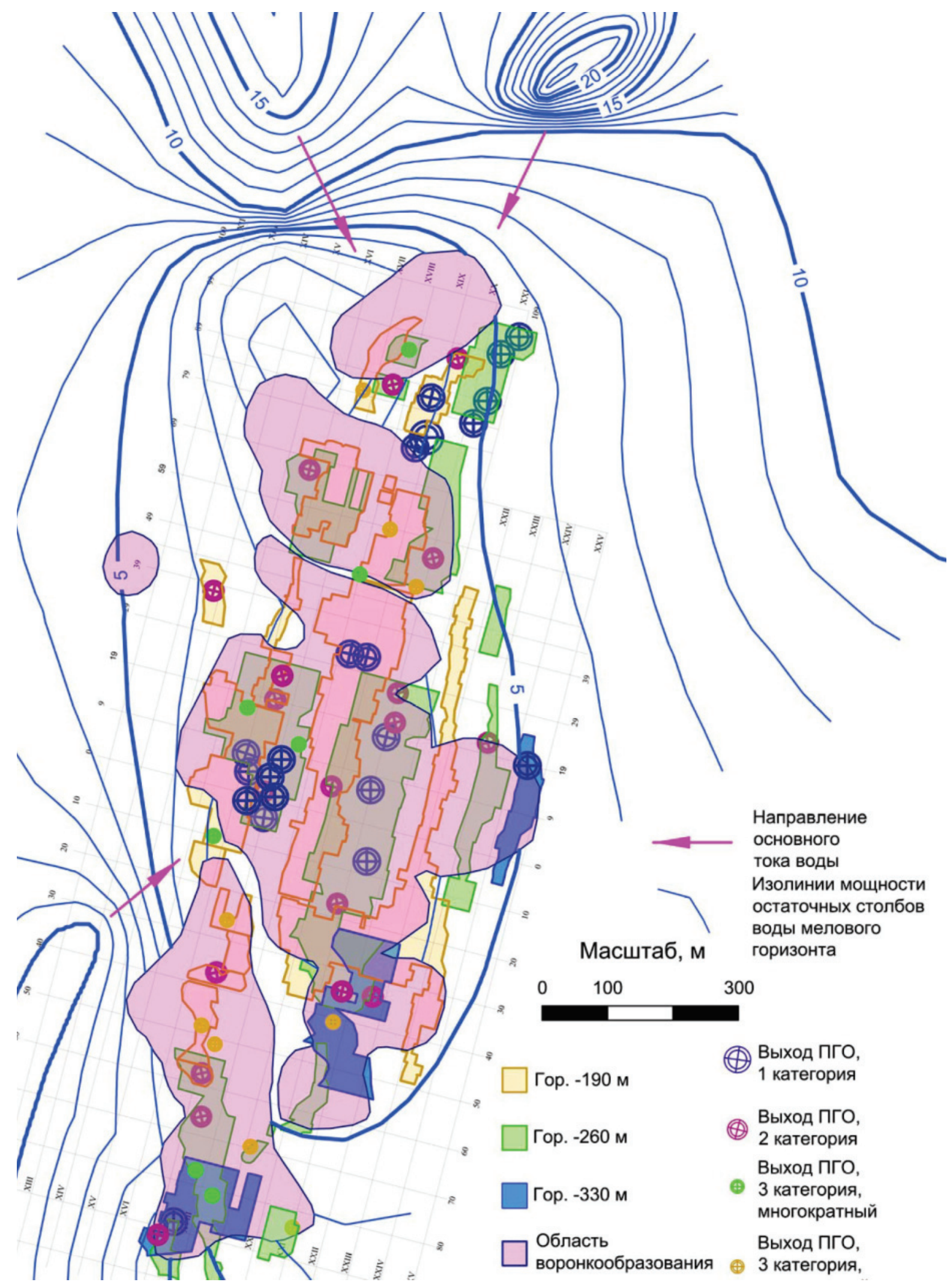

Рис. 3. Распределение мощности остаточных столбов воды в Меловом горизонте

Fig. 3. Contour map of water level in Cretaceous aquifer 
двумя из них. По-видимому, причина концентрации прорывов отложений связана с особенностями водного питания зоны обрушения. Не вызывает сомнений, что гидрогеологические условия массива, окружающего месторождения, оказывают влияние на горнотехническую ситуацию [21, 22]. Для выявления источников водопритоков в область обрушения привлечены данные мониторинга гидрогеологических скважин.

Анализ данных наблюдательных скважин в олигоценовом водоносном горизонте, расположенном на отметке 176 м, показал, что характер водопритока в область обрушения имеет равномерный характер по всей площади обрушения, не может служить источником повышенного водного питания групп воронок северной и центральной.

Другая картина наблюдается при анализе данных гидрогеологических скважин Мелового водоносного горизонта, расположенного на отметке 95 м. На рис. 3 изображено распределение остаточных столбов воды Мелового горизонта. На изображении заметно, что распределение воды в Меловом горизонте неравномерно. В целом по месторождению уровень остаточных столбов составляет около 5-6 м. Выделяются участки, на которых высота столбов значительно превышает среднее значение по месторождению. Один из этих участков расположен на северном фланге месторождения, максимальный уровень воды здесь доходит до 20 м. Другой расположен на юго-западе месторождения, уровень воды достигает 10 м.

Водопритоки из этих областей обеспечивают повышенное питание водой участков обрушения, на которых наблюдается концентрация выходов глинистых отложений на горизонты выпуска.

\section{Результаты анализа}

Результаты проведенных исследований можно свести к нескольким положениям:

1. Область обрушения на поверхности имеет сложное строение, от отдельных выходов воронок до объединенных провалов. Выделяются четыре группы объединенных воронок, вызванные отработкой наиболее крупных рудных тел.

2. Большинство $(70 \%)$ из наиболее масштабных случаев прорывов происходят из области обрушения двух групп воронок - северной и центральной.

\section{СПИСОК ЛИТЕРАТУРЫ}

1. Szwedzicki T. Geotechnical precursors to large-scale ground collapse in mines // International Journal of Rock Mechanics and Mining Sciences. - 2001. - V. 38. - № 7. - P. 957-965.

2. Brady B.H.G., Brown E.T. Rock mechanics: for underground mining. - Dordrecht: Springer Science \& Business Media, 2007. $628 \mathrm{p}$.

3. Sun W., Zhou W., Jiao J. Hydrogeological classification and water inrush accidents in China's coal mines // Mine Water and the Environment. - 2016. - V. 35. - № 2. - P. 214-220. URL: doi.org/10.1007/s10230-015-0363-3 (дата обращения 28.09.2019)
3. Распределение количества прорывов или объемов перенесенных отложений не имеет какоголибо цикличного характера.

4. Основные прорывы приурочены к очистным работам на нижних рабочих горизонтах, в области обрушения северной и центральной групп воронок. Происходят, как правило, во время начальной стадии отработки рудного тела на нижнем горизонте, в дальнейшем частота и объем прорывов снижаются.

5. Необходимым условием формирования масштабных прорывов является повышенная обводненность области обрушения. Источниками повышенного питания групп воронок центральной и северной являются области высоких остаточных водяных столбов Мелового водоносного горизонта.

\section{Заключение}

В результате проведенных работ были определены особенности временного и пространственного распределения прорывов глинистых отложений на горизонты выпуска. На основании механизма формирования и проникновения глинистых масс выделены основные факторы, влияющие на количество осадочных отложений, проникающих в выработки, - обводненность вышележащего массива и нарушенность строения вышележащего массива процессом обрушения кровли. Выделены основные области концентрации выходов осадочных отложений на горизонты выпуска, связанные с обширными областями обрушения, и им соответствующие воронки на земной поверхности.

Достигнута основная цель - определены источники водного питания зоны обрушения в областях прорывов отложений в горные выработки. Ими являются участки Мелового горизонта, расположенные на северном фланге и юго-западе месторождения.

Полученные данные позволяют значительно снизить количество и объем прорывов осадочных отложений на горизонты выпуска. Основным путем снижения прорывов является рациональная организация осушения массива пород вмещающего месторождения, направленная на целевое осушение обводненных участков Мелового горизонта.

4. Seymour C. Mining disasters - What lessons can be learnt // Queensland Mine Safety Conference. - Queensland, Australia, 2005. - P. 19-31. URL: http://www.qldminingsafety.org.au/ dbase_upl/SafeConf05.pdf (дата обращения 28.09.2019).

5. Vutukuri V.S., Singh R.N. Mine inundation-case histories // Mine water and the environment. - 1995. - V. 14. - № 1. P. $107-130$.

6. Job B. Inrushes at British collieries: 1851 to $1970 / /$ Colliery Guardian. - 1987. - V. 235. - № 5. - P. 192-201.

7. Анализ инженерных решений при спасении людей на шахте «Западная-Капитальная» 000 «Компания «Ростовуголь» во время аварии 23.10.03 / С.Г. Пелих, В.В. Родимов, В.Е. Бор- 
зяк, В.П. Шаповалов // Горный информационно-аналитический бюллетень, -2005 . - № 2. - С. 191-193.

8. Трифонова П. «Алроса» начнет восстанавливать рудник «Мир» в 2020 году // Ведомости. 27 апреля 2018. URL: https://www.vedomosti.ru/business/articles/2018/04/27/ 768142-alrosa-nachnet (дата обращения 28.09.2019).

9. Bringemeier $\mathrm{D}$. Inrush and mine inundation - a real threat to $\mathrm{Au}$ stralian coal mines? // International Mine Water Association Annual Conference. - Bunbury, Australia 30 September 2012. URL: https://www.researchgate.net/publication/281593908_Inrush_and_mine_inundation_-_A_real_threat_to_Australian_coal_mines (дата обращения 28.09.2019).

10. Overburden failure and the prevention of water and sand inrush during coal mining under thin bedrock / W. Yang, X. Xia, G. Zhao, Y. Ji, D. Shen // Mining Science and Technology (China). - 2011. - V. 21. - № 5. - P. 733-736.

11. Zhou W., Li G. Impact of karst water on coal mining in North China // Environmental Geology. - 2006. - V. 49. - № 3. P. 449-457. DOI: $10.1007 / \mathrm{s} 00254-005-0102-3$.

12. Дубынин Н.Г., Храмцов В.Ф., Шеховцов В.С. Предотвращение прорывов глинистых пород при разработке рудных месторождений. - Новосибирск: Изд-во ИГД СО АН СССР, 1989. - 124 с.

13. Усанов С.В., Крутиков А.В., Мельник Д.Е. Обеспечение промышленной безопасности при разработке соколовского железорудного месторожжения подземным способом в условиях обводненной налегающей толщи // Проблемы недропользования. - 2018. - № 4. - C. $82-89$. DOI: 10.25635/2313-1586.2018.04.082.

14. Hoek E. Prediction of hazards in underground excavations // IFAC Proceedings Volumes. - 1985. - V. 18. - № 6. - P. 1-5.

15. Казикаев Д.М. Геомеханические процессы при совместной и повторной разработке. - М.: Недра, 1981. - 288 с.

16. Далатказин Т.Ш. Исследование минерального состава глинистых отложений коры выветривания при выполнении геодинамической диагностики для обеспечения безопасности объектов недропользования // Проблемы недропользования. - 2018. № 3. - C. 39-43. DOI: $10.25635 / 2313-1586.2018 .03 .039$.

17. Ведерников А.С. Уточнение сейсмичности месторождений в «асейсмичном» районе республики Казахстан // Проблемы недропользования. - 2018. - № 4. - C. 23-28. DOI: $10.25635 / 2313-1586.2018 .04 .023$

18. Особенности напряженного состояния горного массива Соколовского железорудного месторождения / А.Е. Балек, А.А. Панжин, Ю.П. Коновалова, Д.Е. Мельник // Инновационные геотехнологии при разработке рудных и нерудных месторождений: Междунар. научно-техн. конф. - Екатеринбург, 2018. Отв. за вып. Н.Г. Валиев. - Екатеринбург: УГГУ, 2018. - C. 256-265.

19. Учет специфики комбинированной разработки рудных месторождений при натурных замерах напряженного состояния породного массива / А.Е. Балек, А.А. Панжин, Ю.П. Коновалова, Д.Е. Мельник // Горный журнал. - 2018. - № 4. - С. 20-27. DOI: $10.17580 / \mathrm{gzh} .2018 .04 .04$.

20. Ефремов Е.Ю. Обоснование критерия завершения процесса воронкообразования // Известия Тульского государственного университета. Науки о земле. - 2018. - № 4. - С. 12-22.

21. Пургина Д.В., Кузеванов К.И. Водопритоки в подземные горные выработки под влиянием внешних граничных условий при разработке угольных месторождений (на примере шахты Алексиевская) // Известия Томского политехнического университета. Инжиниринг георесурсов. - 2018. - Т. 329. - № 4. C. $79-96$.

22. Гидрогеологические условия нарыкско-осташкинской площади Ерунаковского района Кузбасса / Е.В. Домрочева, К.И. Кузеванов, А.Г. Гридасов, Д.А. Сизиков // Известия Томского политехнического университета. Инжиниринг георесурсов. 2018. - T. 329. - № 9. - C. 134-142.

Поступила 04.10.2019 2.

\section{Информация об авторах}

$\boldsymbol{E}$ фрелов E.Ю., научный сотрудник Института горного дела Ур0 РАН. 


\title{
CHARACTERISTIC OF MUD INRUSHES DISTRIBUTION FROM CAVED ZONE INTO DEPOSIT LOCATED UNDER SEDIMENTARY STRUCTURE
}

\author{
Evgeniy Yu. Efremov, \\ Efremov-eu@mail.ru \\ Institute of Mining of the Ural Branch of the Russian Academy of Sciences, \\ 58, Mamin-Sibiryak street, Yekaterinburg, 620219, Russia.
}

The relevance of research. Water and mud inrushes into underground working pose a serious threat for underground mining. There was a series of mud inrushes at "Sokolovskaya» mine over the past two decades. The largest of them led to the death of two miners. Recovery of the mine took several months.

The aim of the research is identification of inrushes distribution pattern to reduce the risk of mud inrush into the mine workings under overlying aquifers.

Methods. Analysis of mud inrushes includes identification of spatial and temporal distribution of the accidents occurred from 2003 to 2018; consideration of the mechanism of accumulation and transfer of mud masses from overlying aquifers into mine workings through caved zone and determination of factors affecting the volume of inrushes; geostatistical analysis of aquifer parameters; comparison of aquifer parameters and distribution of inrushes.

Results. The main part of the large inrushes occurred in lower levels under central and north caved zones. They usually occurred during the initial stage of ore body extracting on the lowest level. Further frequency and volume of the inrushes are reduced. A necessary condition for formation of large-scale inrush is high water cut of caved zone. Sources of high water cut of the northern and central caved zones are high water level areas of the Cretaceous aquifer to the north and west of the deposit. The main way to reduce the risk of mud inrush is the targeted drainage of the rock mass around the mine in the Cretaceous aquifer high water level areas.

\section{Key words:}

Funnel of caved zone, caved zone, water inflow, mud inrush, clay minerals, flooding.

\section{REFERENCIES}

1. Szwedzicki T. Geotechnical precursors to large-scale ground collapse in mines. International Journal of Rock Mechanics and Mining Sciences, 2001, vol. 38, no. 7, pp. 957-965.

2. Brady B.H.G., Brown E.T. Rock mechanics: for underground mining. Dordrecht, Springer Science \& Business Media, 2007. $628 \mathrm{p}$.

3. Sun W., Zhou W., Jiao J. Hydrogeological classification and water inrush accidents in China's coal mines. Mine Water and the Environment, 2016, vol. 35, no. 2, pp 214-220. Available at: doi.org/10.1007/s10230-015-0363-3.

4. Seymour C. Mining disasters - What lessons can be learnt. Conference paper: Queensland Mine Safety Conference. 2005. pp.19-31 http://www.qldminingsafety.org.au/_dbase_upl/SafeConf05.pdf (accessed 28 September 2019).

5. Vutukuri V.S., Singh R.N. Mine Inundation-Case Histories. Mine water and the environment, 1995, vol. 14, pp. 107-130.

6. Job B. Inrushes at British collieries: 1851 to 1970. Colliery Guardian, 1987, vol. 235, no. 5, pp. 192-201.

7. Pelikh S.G., Rodimov V.V., Borziak V.E., Shapovalov V.P. Analiz inzhenernykh resheniy pri spasenii ludey na shakhte «Zapadnaya-Kapitalnaya» 000 "Rostov-Ugol» vo vremya avariy 23.10.03 [Analysis of engineer solution when saving people during "Rosstovugol» "Zapadnaya-Kapitalnaya» mine disaster]. Gorny informatsionno-analiticheskiy byulleten, 2005, no. 2, pp. 191-193.

8. Trifonova P. «Alrosa» nachnet vosstanavlivat rudnik «Mir» v 2020 godu [ "Alrosa» will begin recovery of «Mir» mine in 2020]. Vedomosti. 27 April 2018. Available at: https://www.vedomosti.ru/business/articles/2018/04/27/768142-alrosa-nachnet (accessed 28 September 2019).

9. Bringemeier D. Inrush and mine inundation - a real threat to $\mathrm{Au}$ stralian coal mines? International Mine Water Association Annual Conference. Bunbury, Australia, 2012 Available at: https://www.researchgate.net/publication/281593908_Inrush_and_mine_inundation_-_A_real_threat_to_Australian_coal_mines (accessed 28 September 2019).
10. Yang W., Xia X., Zhao G., Ji Y., Shen D. Overburden failure and the prevention of water and sand inrush during coal mining under thin bedrock. Mining Science and Technology (China), 2011, vol. 21, no. 5, pp. 733-736.

11. Zhou W., Li G. Impact of karst water on coal mining in North China. Environmental Geology, 2006, vol. 49, no. 3, pp. 449-457. DOI: $10.1007 / \mathrm{s} 00254-005-0102-3$

12. Dubinin N.G., Khramtsov V.F., Shekhovtsov V.S. Predoturashenie proryvov glinistykh porod pri razrabotke rudnykh mestorogdeniy [Mud inrush prevention on ore mines]. Novosibirsk, IGD S0 USSR Publ., 1989. 124 p.

13. Usanov S.V., Krutikov A.V., Melnik D.E. Ensuring of industrial safety when developing sokolovskiy iron-ore deposit by underground method in terms of flooded overlapping strata. Ploblems of mining, 2018, no. 4, pp. 82-89, DOI: 10.25635/2313-1586.2018.04.082. In Rus.

14. Hoek E. Prediction of hazards in underground excavations. IFAC Proceedings Volumes, 1985, vol. 18, no. 6, pp. 1-5

15. Kazikaev D.M. Geomekhanicheskie protsessy pri soumestnoy i povtornoy podrabotke [Geomechanical processes during combined and second mining]. Moscow, Nedra Publ., 1981. 288 p.

16. Dalatkazin T.S. Research of the mineral composition of clayey deposits of the weathering crust during geodynamic diagnostics for ensuring the safety of subsoil use objects. Problems of mining, 2018, no. 3, pp. 39-43. In Rus. DOI: 10.25635/2313-1586.2018.03.039.

17. Vedernikov A.S. Deposits seismicity study of a «nonseismic» region of the Kazakhstan. Problems of mining, 2018, no. 4, pp. 23-28. In Rus. DOI: 10.25635/2313-1586.2018.04.023.

18. Balek A.E., Panzhin A.A., Konovalova Yu.P., Melnik D.E. Osobennosti napryazhenogo sostoyaniya gornogo massiva Sokolovskogo zhelezorudnogo mestorogdeniya [Paricular properties of rock stress conditions of Sokolovskoe ore deposit]. Innovatsionnnye geotekhnologii pri razrabotke rudnykh i nerudnykh mestorozhdeny. Mezhdunarodnaya nauchno-tekhnicheskaya konferentsiya [Conference paper: Innovation technology for extraction of ore and industrial minerals]. Yekaterinburg, 2018. pp. 256-265.

19. Balek A.E., Panzhin A.A., Konovalova Yu.P., Melnik D.E. In-situ stress measurement in rocks, considering specificity of hybrid 
mining. Mining journal, 2018, no. 4, pp. 20-27. In Rus. D0I: 10.17580 /gzh.2018.04.04.

20. Efremov E. Y. Rationale of cave-in process consummation criterion. News of the Tula state university. Sciences of Earth, 2018, no. 4, pp. 12-22. In Rus.

21. Purgina D.V., Kuzevanov K.I. Water inflow into mine under the influence of external boundary conditions at coal deposit exploitation (Kuzbass). Bulletin of the Tomsk Polytechnic University. Geo Assets Engineering, 2018, vol. 329, no. 4, pp. 79-96. In Rus.
22. Domrocheva E.V., Kuzevanov K.I., Gridasov A.G., Sizikov D.A. Hydrogeological conditions of naryksko-ostashkin area in Eunakovo region in Kuzbass. Bulletin of the Tomsk Polytechnic University. Geo Assets Engineering, 2018, vol. 329, no. 9, pp. 134-142. In Rus.

Received: 4 October 2019.

\section{Information about the authors}

Evgeniy Yu. Efremov, researcher, Institute of Mining of the Ural Branch of the Russian Academy of Sciences. 